\title{
Numerical Investigation of Corrugated Wire Mesh Laminate
}

\author{
Jeongho Choi, ${ }^{1}$ Krishna Shankar, ${ }^{2}$ and Murat Tahtali ${ }^{2}$ \\ ${ }^{1}$ Light Metal Division, Materials Deformation Department, Korea Institute of Materials Science, Changwon 642-831, Republic of Korea \\ ${ }^{2}$ School of Engineering and Information Technology, University of New South Wales, Australian Defence Force Academy, \\ Canberra, ACT 2600, Australia
}

Correspondence should be addressed to Jeongho Choi; choicaf@gmail.com

Received 4 October 2012; Accepted 11 January 2013

Academic Editor: İlker B. Topçu

Copyright (C) 2013 Jeongho Choi et al. This is an open access article distributed under the Creative Commons Attribution License, which permits unrestricted use, distribution, and reproduction in any medium, provided the original work is properly cited.

\begin{abstract}
The aim of this work is to develop a numerical model of Corrugated Wire Mesh Laminate (CWML) capturing all its complexities such as nonlinear material properties, nonlinear geometry and large deformation behaviour, and frictional behaviour. Development of such a model will facilitate numerical simulation of the mechanical behaviour of the wire mesh structure under various types of loading as well as the variation of the CWML configuration parameters to tailor its mechanical properties to suit the intended application. Starting with a single strand truss model consisting of four waves with a bilinear stress-strain model to represent the plastic behaviour of stainless steel, the finite element model is gradually built up to study single-layer structures with 18 strands of corrugated wire meshes consistency and double- and quadruple-layered laminates with alternating crossply orientations. The compressive behaviour of the CWML model is simulated using contact elements to model friction and is compared to the load-deflection behaviour determined experimentally in uniaxial compression tests. The numerical model of the CWML is then employed to conduct the aim of establishing the upper and lower bounds of stiffness and load capacity achievable by such structures.
\end{abstract}

\section{Introduction}

Corrugated wire mesh laminates (CWMLs) are a class of open cell structures fabricated with corrugated wire mesh layers bonded together to form a low-density structure with high strength and stiffness [1]. CWML has potential for many applications such as heat exchanger units [2], in core materials for sandwich structures [3], and other engineering applications which require a large ratio of open space to the total volume [4]. One of the main areas in which CWML offers potential for application is in biomedical engineering [5], for the use as orthopaedic implants to replace cortical or cancellous bone. The relatively high strength and low density of CWML and its open cell configuration facilitate tissue regeneration and bone ingrowth, while providing support for the load applied to the bone. In comparison with open cell metal foams [6], CWML has the advantage that the configuration of the open cell structure can be controlled during manufacture and tailored to provide the desired open space ratio and relative stiffness and strength to suit the application. CWML for biomedical applications are usually fabricated with biocompatible materials such as 316 stainless steel [7], chrome cobalt alloy, and titanium alloys $[8,9]$. Previous studies on corrugated wire mesh laminates and similar periodic synthesized cellular structures [10] such as microtruss laminates [11] have mainly focused on fabrication techniques and experimental determination of mechanical properties of the structure [12]. Fabricated samples are shown in Figure 1. The figure shows fabricated CWML samples as plain mesh, corrugated mesh, and bonded multilayer CWML sample.

Crimping is a process to make corrugations in wire mesh. A plain type of cylindrical metal wire mesh sheet as shown in Figure 1(a) is put into the spur gear to produce corrugated wire mesh as shown in Figure 1(b). It is a simple process in which the plain mesh is put into designed spur gear to make corrugation wave. Bonded CWML sample shown in Figure 1(c) is made laminated with a single corrugated wire mesh at \pm 90 degrees. The samples are prepared by arranging in the predetermined sequence required for the laminates. The solder material, Eutectic Rod 157PA, which comes in the form of a paste and includes a flux, which contained $95 \%$ tin and $5 \%$ silver (95Sn-5Ag), was applied to the joints of the samples manually with a fine brush. It is generally 


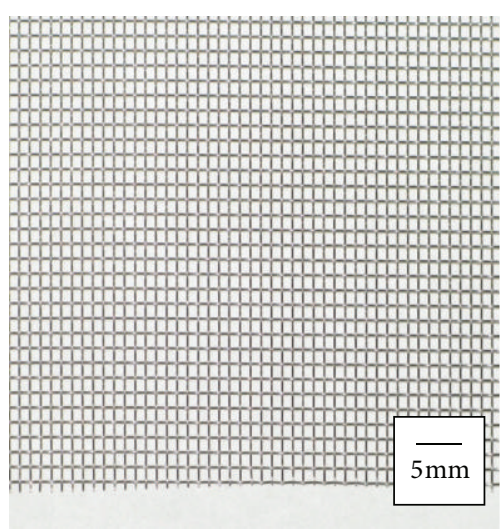

(a) Plain mesh

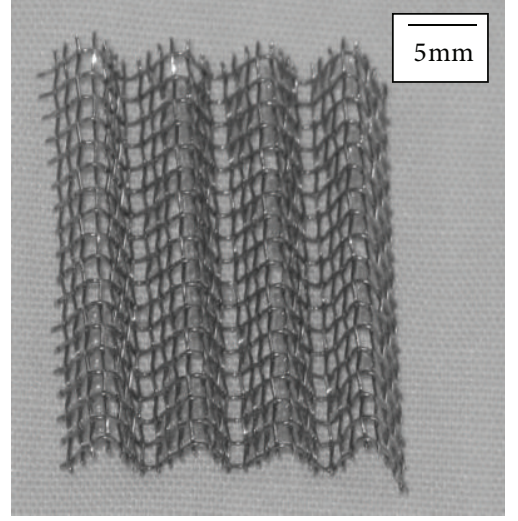

(b) Corrugated wire mesh

FIGURE 1: Fabricated CWML.

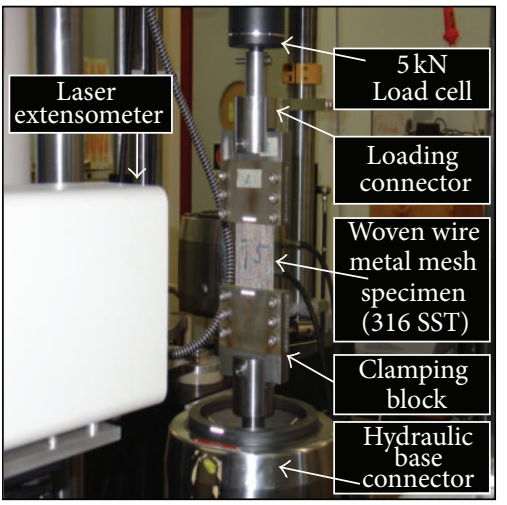

(a)

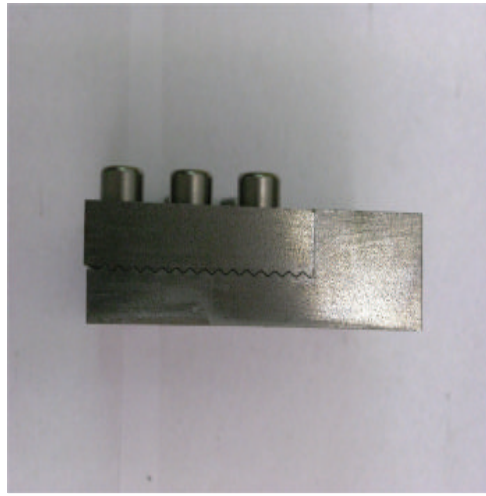

(b)

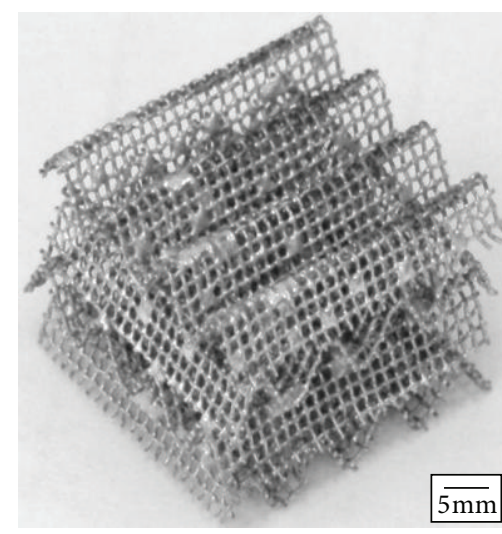

(c) Bonded CWML

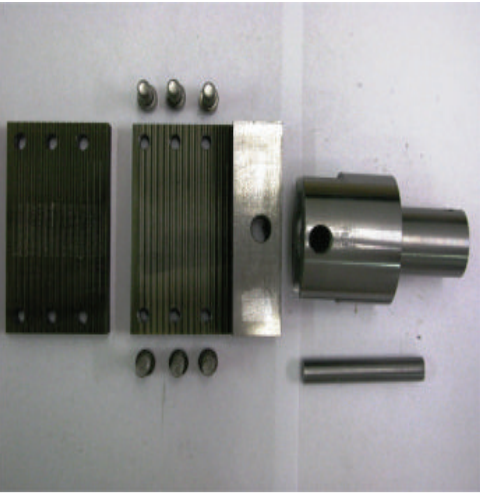

(c)

FIgURE 2: (a) Equipment, (b) designed clamp, and (c) designed clamps.

used for joining and repairing of stainless steel. Its features include high fluidity, full joint penetration, very low heat input, excellent corrosion resistance, and ease of use. Thus, the bonded CWML specimen is made by heat treatment at $225^{\circ} \mathrm{C}$ for 30 minutes with supplying the inert Argon gas as 1-5 MPa intaking gas pressure. The washed samples were cleaned again using $99.9 \%$ purified methanol for 10 minutes. The fabricated sample is used for a uniaxial compression test.

Therefore, this paper focuses on an effective stiffness before yielding and the yield load of a finite element CWML model because finite element modelling of CWML is an area that has largely been unexplored. Moreover, the CWML model is validated by the experiment of the fabricated sample for effective stiffness before yielding and yield load.

\section{Wire Mesh Characterisation}

For the tension test, sample is a stainless steel AISI 316 woven mesh with 55 wires horizontally as shown in Figure 1(a). The mesh has a wire diameter of $0.22 \mathrm{~mm}$ included with an opening width of $0.95 \mathrm{~mm}$. Five sheets of the woven wire mesh are used, and the original length before testing is $80.26 \mathrm{~mm}$ (SD 5.27, where SD is a standard deviation).
Figure 2 describes designed equipments (a) and clamps (b, c). Laser extensometer is used to measure displacement. Computer shows a plot for load against a changing displacement. Loading connector at the top, hydraulic-base connector, and clamping block at the top/bottom are designed specifically for the tension test. Clamping block at top/bottom has a total width of $100 \mathrm{~mm}$, total height of the $100 \mathrm{~mm}$, and grooved height in middle side $65 \mathrm{~mm}$. In Figure 2(c), each number shows separated parts before connecting the mesh sheet sample. Thus, the clamped block in either top or bottom is the same designed clamp. However, hydraulic-based clamp at top side has longer length than that at bottom side because top side needs a deeper length in connector; that is, as base plate in the mechanical machine is moving down, top $5 \mathrm{kN}$ load cell connected with top loading connector is applied to the mesh specimen.

The tension test is conducted in a MTM (Mechanical Testing Machine, INSTRON-Model 1342, INSTRON Co. Ltd.). A $5 \mathrm{kN}$ load cell is used and the crosshead speed is set at $5 \mathrm{~mm} / \mathrm{min}(0.083 \mathrm{~mm} / \mathrm{s})$. Displacement in the tension test is measured by a laser extensometer [14] with a scan rate of 100 scans per second. It is a noncontact strain measurement with a maximum displacement of $100 \mathrm{~mm}$ and a maximum target 


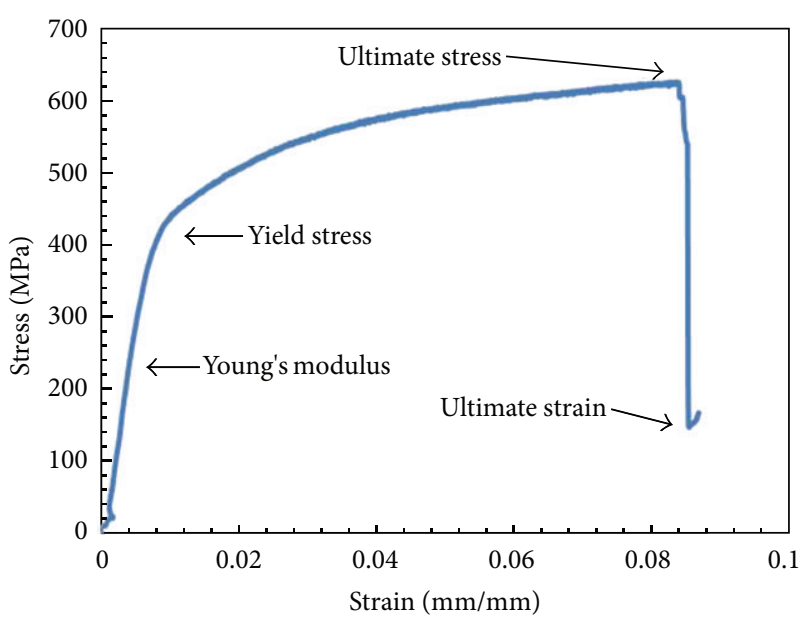

(a)

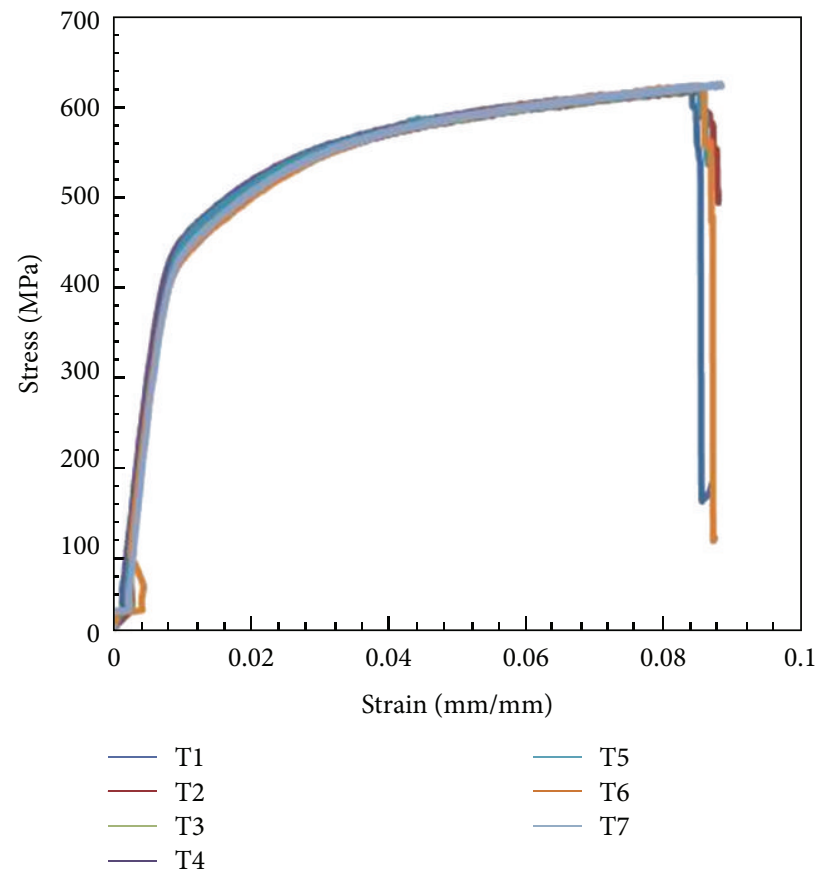

(b)

FIgURE 3: Stress-strain diagram in (a) and nominal stress as a function of nominal strain in (b).

distance of $380 \mathrm{~mm}$. Target distance used in the tension test is $305 \mathrm{~mm}$; that is, the laser extensometer is placed at a distance of $305 \mathrm{~mm}$ from the specimen.

Thus, Figure 3 shows stress-strain diagram and indication of yield stress, Young's modulus, ultimate stress, and ultimate strain. Yield stress is a stress to make yielding, which means a breakdown of the material, and to cause it to deform permanently. Young's modulus represents the slope of the initial straight lined portion of the stress-strain diagram up to the proportional limit. Ultimate stress is the maximum stress on the stress-strain curve. Ultimate strain is the strain when material fails under the tension test. Therefore, after the experiment, average yield stress is $382.99 \mathrm{MPa}$ (SD
0.38), average elastic modulus is $61048 \mathrm{MPa}$ (SD 3556.09), average ultimate stress is $627.55 \mathrm{MPa}$ (SD 3.20), yield strain $0.00629 \mathrm{~mm} / \mathrm{mm}$, and ultimate strain is $0.086 \mathrm{~mm} / \mathrm{mm}$ (SD $0.003)$.

\section{Development of the CWML Model}

For a CWML model development, eight parts are investigated: CWML geometry, geometry of a single corrugation, meshing, boundary condition, material properties, structural analysis, linear buckling analysis, and friction.

3.1. CWML Geometry. A one-layer CWML structure was created by eighteen wires which is four wave with a single strand, BEAM189, and a curved wire model; CWML geometry for the simulation is developed as shown in Figure 4 as one layer to four layer. Two-layer model and four-layer model are based on one layer: they are developed as $\pm 90^{\circ}$ rotated sandwich structure. Each model is to be validated with experiment in a subsequent chapter. Note that, for the developing CWML model in Figure 4, it is assumed that all contact points in each single strand or in each layer are defined as bonded perfectly.

3.2. Geometry of a Single Corrugation. The basic geometry of a single wave for the FE model is a triangular or curved model as shown in Figure 5. Both models are based on geometrical dimensions of $0.22 \mathrm{~mm}$ wire diameter, $3 \mathrm{~mm}$ height of wave $H_{0}$, and $5 \mathrm{~mm}$ bottom length $L_{0}$, where $H_{0}$ is total height, $L_{0}$ is total base length per a corrugation, and $\varphi$ is a corrugation angle. However, the curved model has a curved line at vertex or bottom within $H_{0}$ and $L_{0}$. For the curved model, curvature radius, $R$, is $0.25 \mathrm{~mm}$.

3.3. Meshing. The beams forming the single wave of a wire mesh can be represented by line model with BEAM189 element type. Typically, in order to determine the appropriate mesh density for an analysis, the results of a preliminary analysis are compared with known analytical results. Then, the mesh is refined until the discrepancy between known and calculated results is acceptable. A mesh sensitivity analysis is done with applied material properties of $193 \mathrm{GPa}$ Young's modulus, and 0.25 Poisson's ratio. A $100 \mathrm{~N}$ load is applied at the vertex in the downward vertical direction and the bottom is fixed. The meshing for the curved model is slightly more complex than the sharp model, because instead of just two lines, a curved model has 5 lines which correspond to the curvature at vertex and bottom in addition to the two sides. Same material properties and model geometry are used as before. Meshing with line divisions is coarse and fine meshing shown in Figure 6.

Then, Figure 6 shows an increasing total number of element based on line division in side beam and curved beam on the top or the bottom. The percentage of error is $0.007 \%$ from 10 elements to 16 elements. Either coarse or fine meshing as has almost the same displacement after 16 total elements. These imply meshing that any meshing number shows the same displacement. 


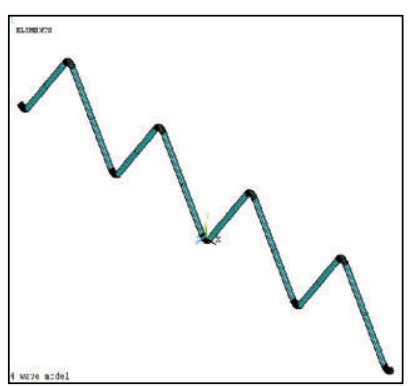

(a)

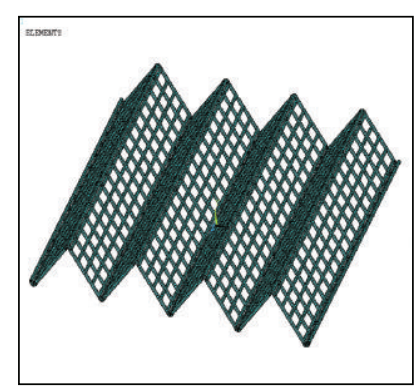

(b)

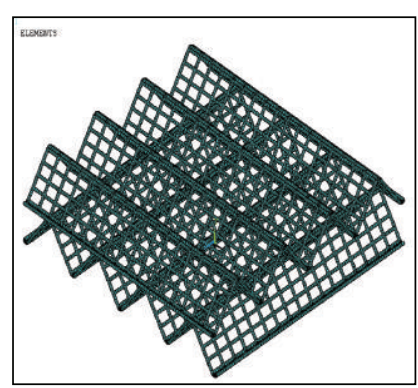

(c)

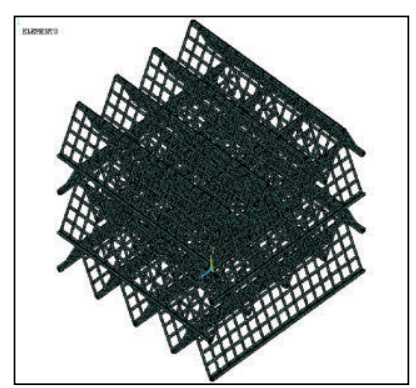

(d)

FIGURE 4: Four-wave single corrugation and CWML geometry.

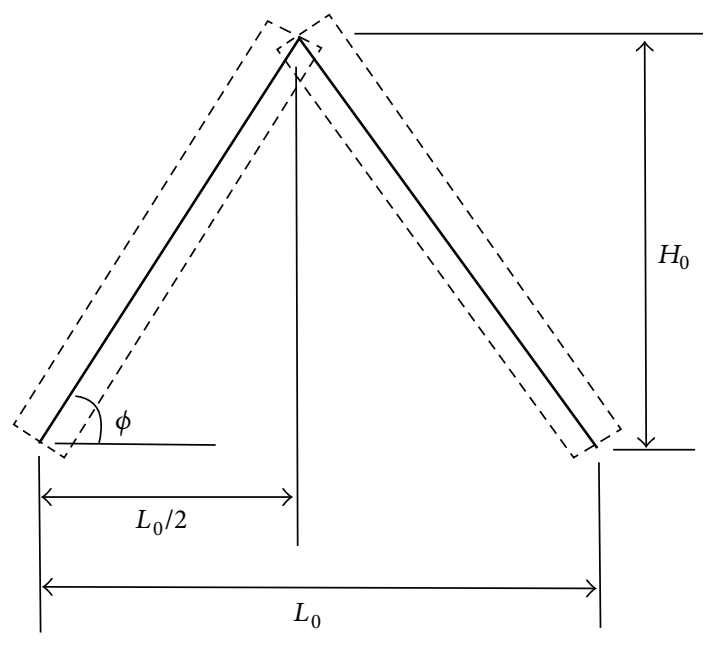

FIGURE 5: Unit model: sharp model.

3.4. Boundary Conditions. Boundary condition to the nodes at the bottom of the single wave model is three cases such as pinned, free, and friction. The pinned case corresponds to no displacement in vertical direction. The free case corresponds to move horizontally as free. The boundary condition chosen for the analysis is a pinned case for the maximum friction coefficient study and a free case for the minimum friction coefficient study. The frictional case relates more realistically to the actual loading of CWML. Different friction coefficients ranging from 0 to 0.8 are applied to observe the effect of friction on the load-displacement behaviour. It has been reported that the maximum friction coefficient number for a metal-metal interface is around 0.8 . In order to simulate a compression loading of the CWML, a downward vertical displacement loading is applied to the vertex point. In our study, a $0.1 \mathrm{~mm}$ displacement is applied to the node at the apex in the $-Y$ direction.

3.5. Material Property. The bilinear assumption allows the user to define a tangential modulus in addition to Young's modulus. A bilinear stress-strain curve is shown in Figure 7.

Young's modulus defines the stiffness of the material up to the yield point. After yield, a tangential modulus is
TABLE 1: Material properties of 316 steel wire mesh.

\begin{tabular}{lcc}
\hline Properties & $\begin{array}{c}\text { Linear isotropic } \\
\text { hardening } \\
\text { material model }\end{array}$ & $\begin{array}{c}\text { Bilinear } \\
\text { isotropic } \\
\text { hardening } \\
\text { material model }\end{array}$ \\
\hline Density $\left(\mathrm{kg} / \mathrm{mm}^{3}\right)$ & $7.99 \times 10^{3}$ & $7.99 \times 10^{3}$ \\
Young's modulus, $E(\mathrm{GPa})$ & 61 & 61 \\
Poisson's ratio & 0.25 & 0.25 \\
Yield strength, $\sigma_{\mathrm{YS}}(\mathrm{MPa})$ & - & 383 \\
Ultimate strength, $\sigma_{\mathrm{ULT}}(\mathrm{MPa})$ & - & 627.5 \\
Ultimate strain, $\varepsilon_{\mathrm{ult}}(\mathrm{mm} / \mathrm{mm})$ & - & 0.086 \\
Tangent modulus, $E_{T}(\mathrm{MPa})$ & - & 3056 \\
\hline
\end{tabular}

defined to model the stiffness. In the figure, Young's modulus is $E$, yield stress is $\sigma_{\mathrm{YS}}$, ultimate stress is $\sigma_{\mathrm{ULT}}$, and tangent modulus is $E_{T}$. The material properties of type 316 stainless steel obtained from the manufacturers of the metal mesh are shown in Table 1.

3.6. Structural Analysis. This section shows structural analysis as small deformation and large deformation. Applied model is two types of geometry as sharp and curved. The boundary condition is $0.1 \mathrm{~mm}$ displacement at vertex and fixed bottom points. The used material model is bilinear isotropic hardening shown in Table 1. The sharp or curved model shows the same effective stiffness before yielding with using linear or bilinear material. As increasing radius in the curved model, effective stiffness before yielding, yield load, and effective stiffness after yielding are decreased. So, total simulated results are plotted in Figure 8 by small deformation as LD OFF and large deformation as LD ON. By small deformation, the sharp or curved model shows bilinear line. With large deformation, the sharp or curved model shows the same effective stiffness before yielding as small deformation, but it presents a decreased effective stiffness after yielding. From the large deformation in the curved model, as increasing radius, effective stiffness before yielding, yield load, and effective stiffness after yielding are decreased.

Thus, Table 2 summarizes an effective stiffness before yielding and yield load by small and large deformation. 
TABLE 2: Effect of bilinear material model ( $R$ is curved radius).

\begin{tabular}{|c|c|c|c|c|c|c|c|c|}
\hline & \multicolumn{4}{|c|}{ Small deformation (LD OFF), bilinear material } & \multirow{2}{*}{\multicolumn{4}{|c|}{$\begin{array}{l}\text { Large deformation (LD ON), bilinear material } \\
\text { Curved model }\end{array}$}} \\
\hline & \multirow{3}{*}{ Sharp model } & \multicolumn{3}{|c|}{ Curved model } & & & & \\
\hline & & & & & Sharp model & & & \\
\hline & & $R=0.125$ & $R=0.25$ & $R=0.375$ & & $R=0.125$ & $R=0.25$ & $R=0.375$ \\
\hline $\begin{array}{l}\text { Effective stiffness before } \\
\text { yielding }(\mathrm{N} / \mathrm{mm})\end{array}$ & 2252.39 & 1603.79 & 1210.29 & 964.29 & 2218.72 & 1578.07 & 1237.70 & 937.69 \\
\hline Yield load (N) & 12.36 & 3.86 & 2.90 & 2.69 & 11.45 & 3.73 & 2.92 & 2.69 \\
\hline $\begin{array}{l}\text { Effective stiffness after } \\
\text { yielding }(\mathrm{N} / \mathrm{mm})\end{array}$ & 9.05 & 20.90 & 15.48 & 13.82 & -199.98 & -38.21 & -27.25 & -17.96 \\
\hline
\end{tabular}

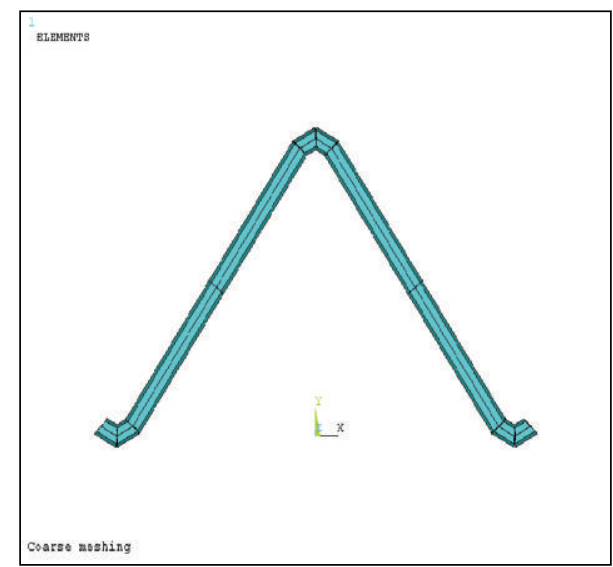

(a)

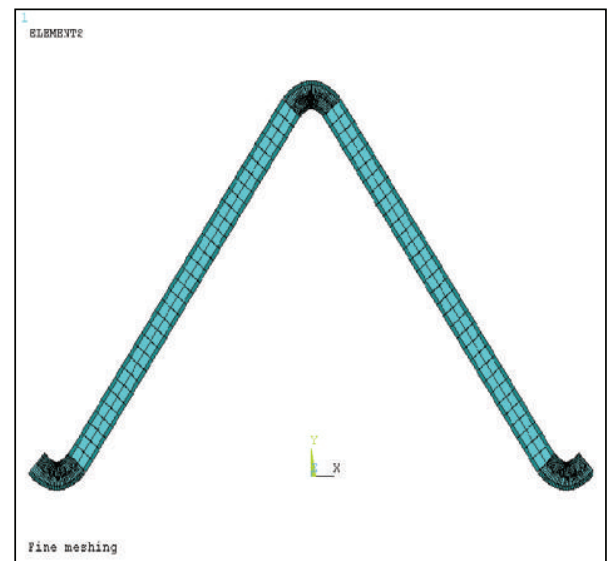

(b)

FIGURE 6: Mesh sensitivity for curved model.

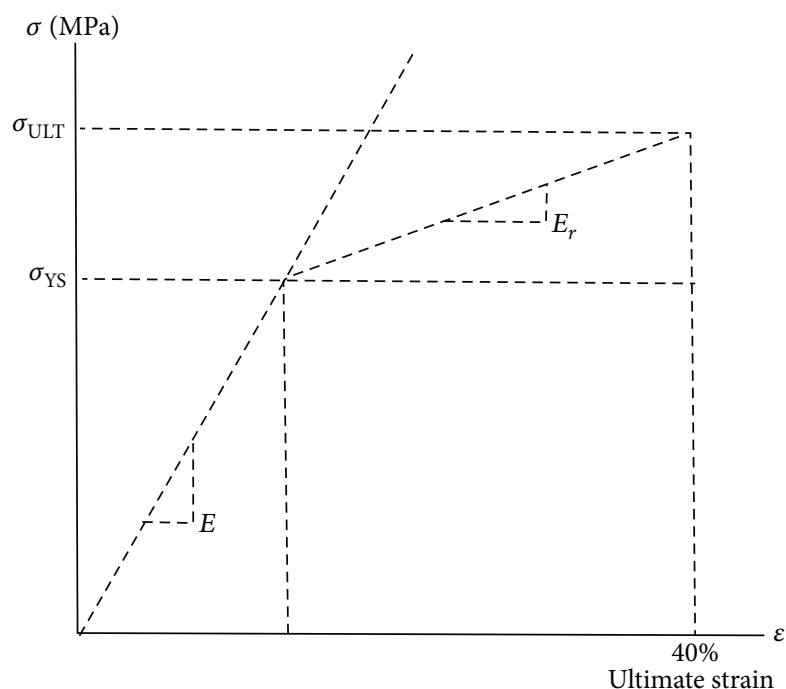

FIGURE 7: Stress-strain diagram.

Effective stiffness before yielding in the sharp model has a higher value than the curved model. That is, as curved radius in the curved model is decreased, effective stiffness before yielding in the curved model has a lower value than the sharp model. In either small or large deformation, they have almost the same effective stiffness before yielding. For yielding, sharp model needs a higher load than curved model. As curved radius in the curved model is increased, yield load in the curved model is decreased.

3.7. Linear Buckling Analysis. Eigen value buckling analysis predicts the buckling strength of an ideal elastic structure [15]. Applied boundary condition is pinned/fixed all bottom points, $1 \mathrm{~N}$ applied at vertex downward. With each boundary condition as pinned or fixed all bottom points, critical buckling load against mode number and mode shape are investigated. Applied model is one corrugated model. The material model is a linear isotropic hardening as shown in Table 1. Thus, Table 3 shows simulated results of critical buckling load for sharp or curved model as pinned/fixed bottom. As increasing the mode number, critical buckling load is increased in either sharp or curved model by pinned or fixed bottom.

Figure 9 shows critical buckling load against mode number. The sharp or curved model has almost the same critical buckling load. When both models use fixed bottom, the critical buckling load is increased.

Figure 10 shows mode shape. Mode 1 shows both side beams buckled to the right direction. Mode 2 shows both side 
TABLE 3: Critical buckling load when applied load as $1 \mathrm{~N}$ is at the vertex and pinned bottom.

\begin{tabular}{|c|c|c|c|c|}
\hline \multirow{2}{*}{ Mode } & \multicolumn{2}{|c|}{ FE sharp model } & \multicolumn{2}{|c|}{ FE curved model $(R=0.25 \mathrm{~mm})$} \\
\hline & Pinned (N) & Fixed $(\mathrm{N})$ & Pinned $(\mathrm{N})$ & Fixed $(\mathrm{N})$ \\
\hline 1 & 22.1 & 45.2 & 22.3 & 47.8 \\
\hline 2 & 45.2 & 88.4 & 43.9 & 89.2 \\
\hline 3 & 88.3 & 133.6 & 88.4 & 133.9 \\
\hline 4 & 133.5 & 180.8 & 134.4 & 184.2 \\
\hline
\end{tabular}

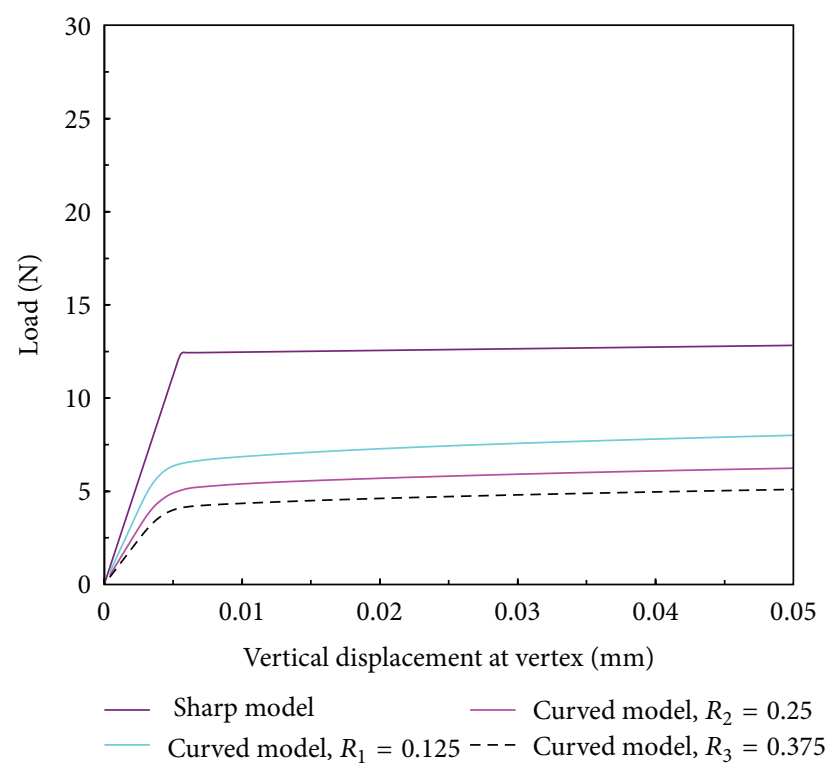

(a) LD OFF

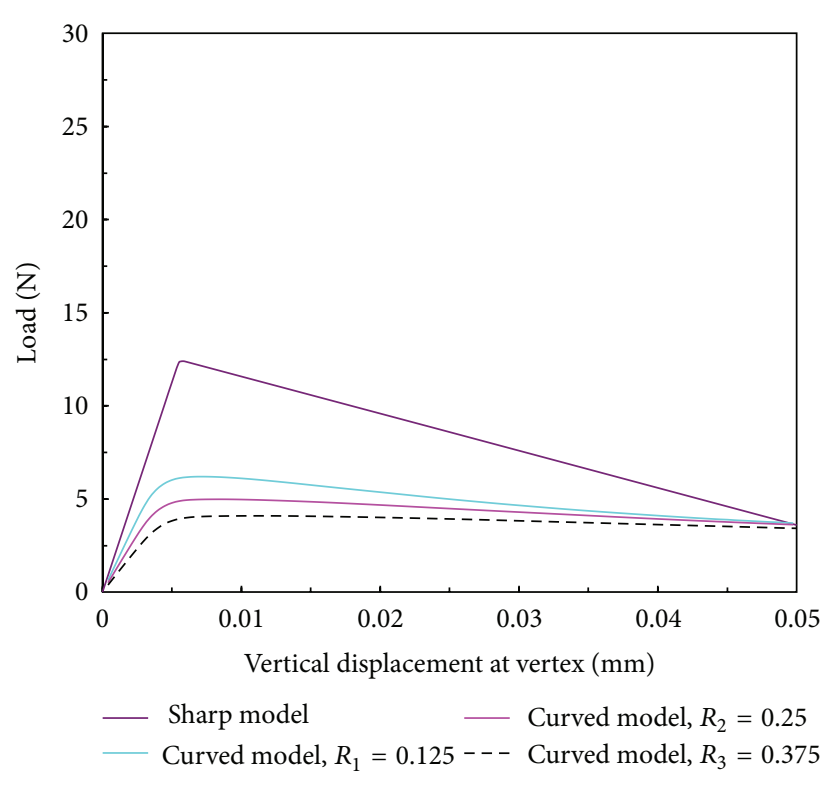

(b) LD ON

FIGURE 8: Load against vertical displacement at vertex for one corrugation model as pinned bottom by small deformation or large deformation.

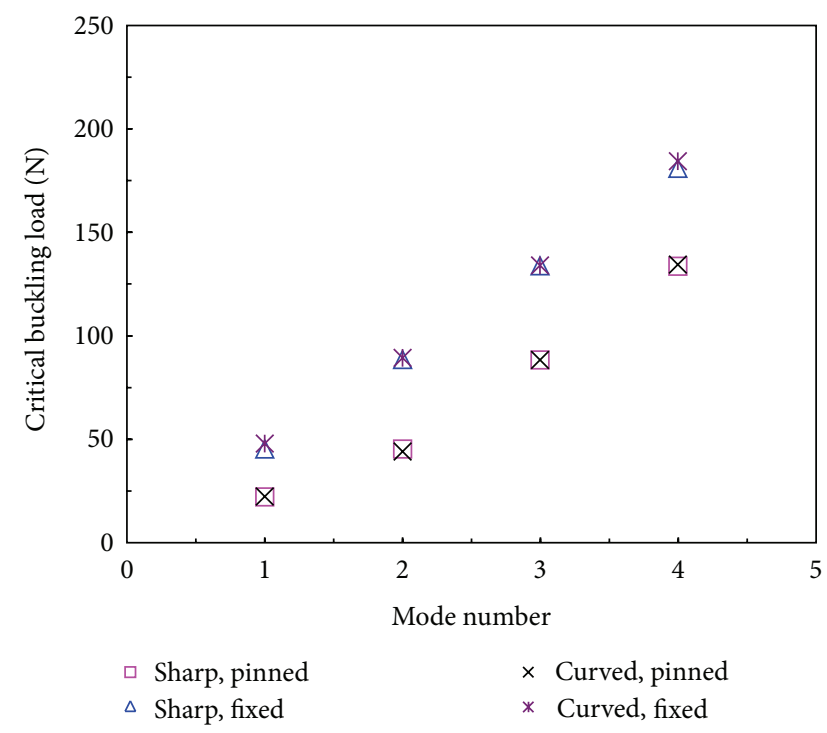

Figure 9: Critical buckling load against mode number (curved model is based on $R=0.25 \mathrm{~mm}$ ). beams buckled symmetrically. Mode 3 shows both side beams buckled as S-curve shape and moved to the right direction. Mode 4 shows both side beams buckled symmetrically as Scurve shape.

In four wave model, critical buckling load is increased as increasing mode number when it uses pinned bottom. However, it is a constant value in every four mode when it uses fixed bottom because fixed bottom implies no rotation. This is shown in Figure 11(a). As example, mode shape for mode 4 by either fixed or pinned bottom is shown in Figures 11(b) and 11(c). In Figure 11(b), it shows buckling mode shape as fixed bottom. In Figure 11(c), it is a buckling mode shape as pinned bottom. This refers to fixed bottom embody stiff than pinned mode shape.

3.8. Friction. Three different kinds of boundary conditions may be applied to the nodes at the bottom of the single wave (or to the end nodes of a multiwave model) as shown in Figure 12: (a) hinged with no translational freedom, (b) hinged with translational freedom in the horizontal 


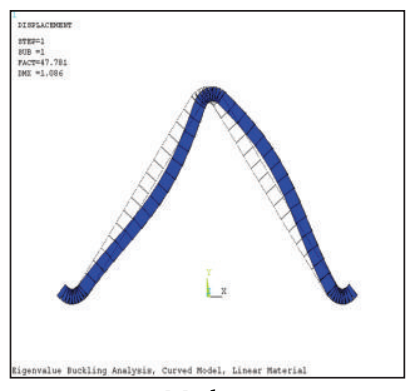

Mode 1

(a)

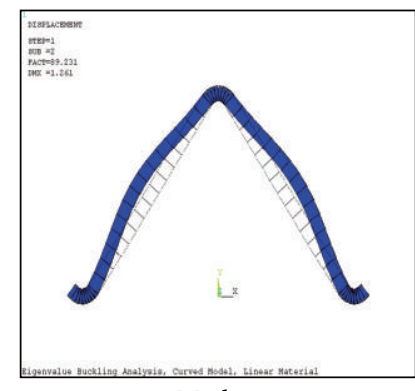

(b)

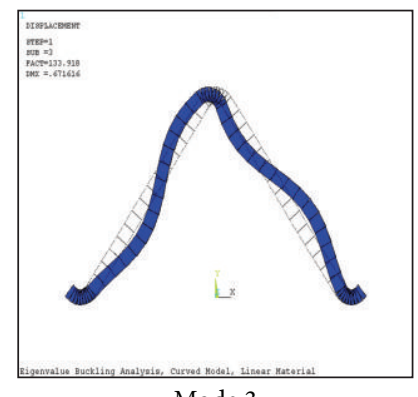

Mode 3

(c)

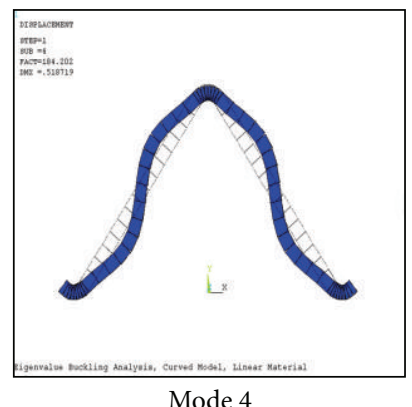

(d)

FIgURE 10: Mode shape in either pinned or fixed bottom.
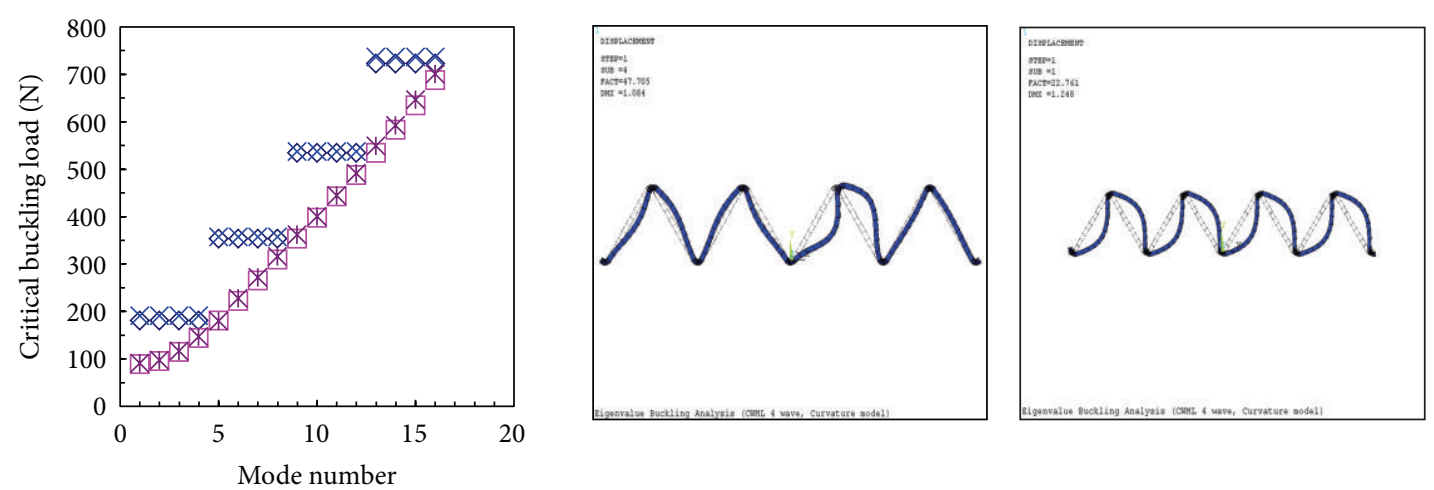

- Sharp, fixed $\quad \times$ Curved, fixed

$\square$ Sharp, pinned $*$ Curved, pinned
(a) Critical buckling load
(b) Fixed bottom
(c) Pinned bottom

FIgURE 11: Critical buckling load and mode shape in mode 4 (curved model is based on $R=0.25 \mathrm{~mm}$ ).

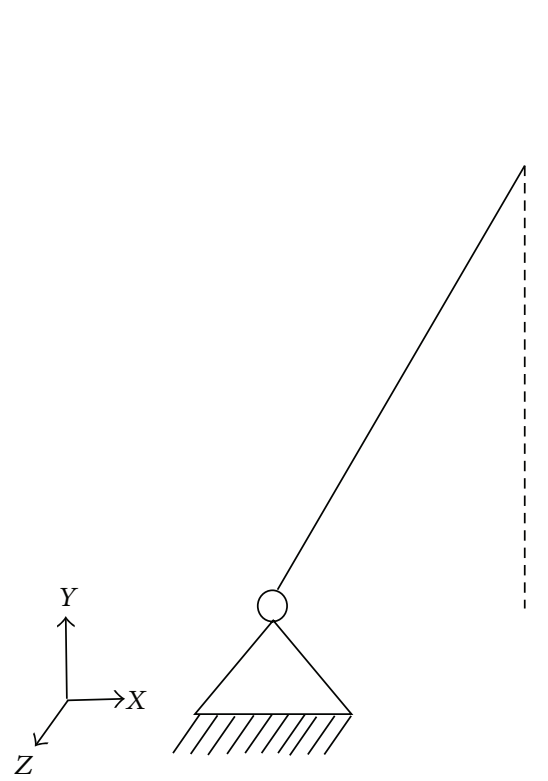

(a)

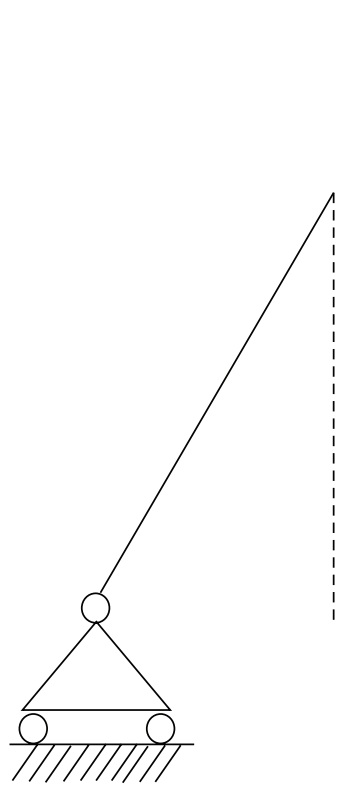

(b)

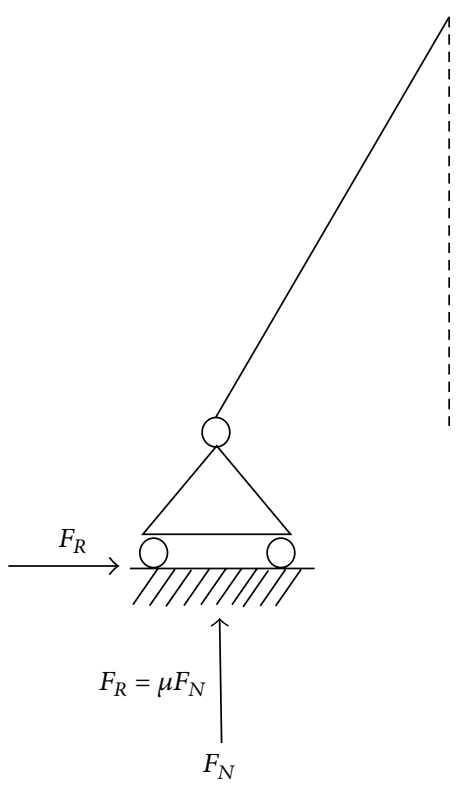

(c)

FIGURE 12: Boundary conditions for the outer bottom nodes. 


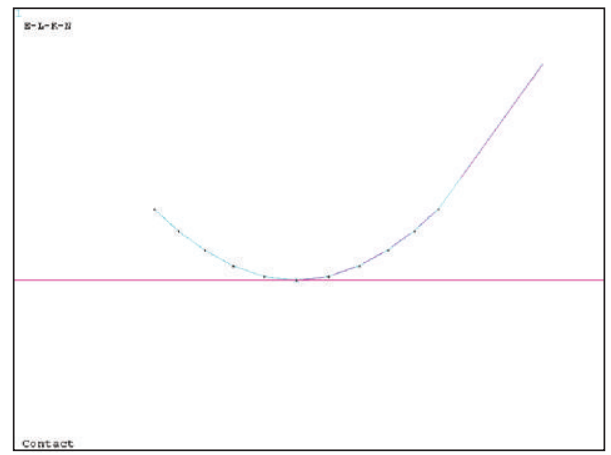

FIGURE 13: Node-line contact.

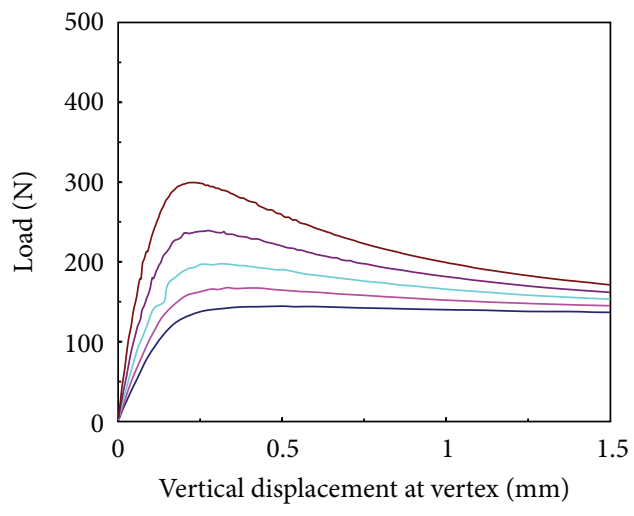

$\begin{aligned}-\mu & =0.2 \quad-\mu=0.35 \\ -\mu & =0.25 \quad-\mu=0.4 \\ \mu & =0.3\end{aligned}$

(a) Friction

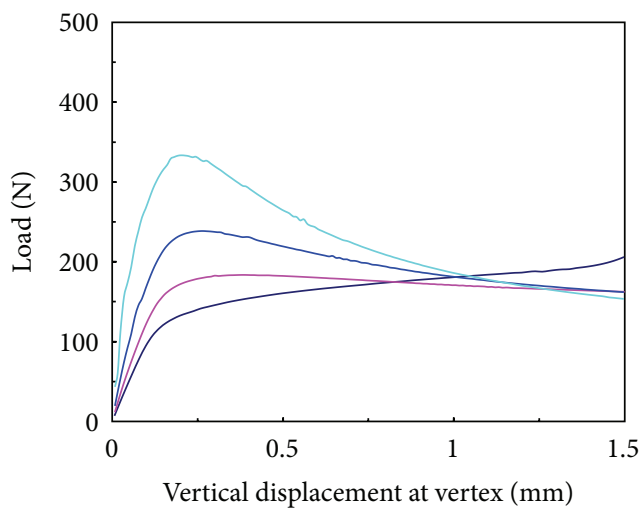

$-H=1.5_{-} \mu=0.35-H=3.5_{-} \mu=0.35$

$-H=2.5 \_\mu=0.35-H=4.5 \_\mu=0.35$

(b) Height

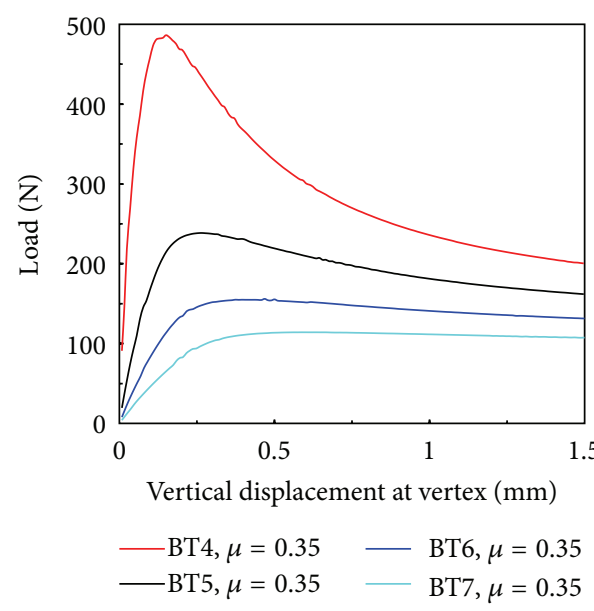

(c) Base length

FIGURE 14: Load against vertical displacement at vertex for the CWML 1-layer model. 


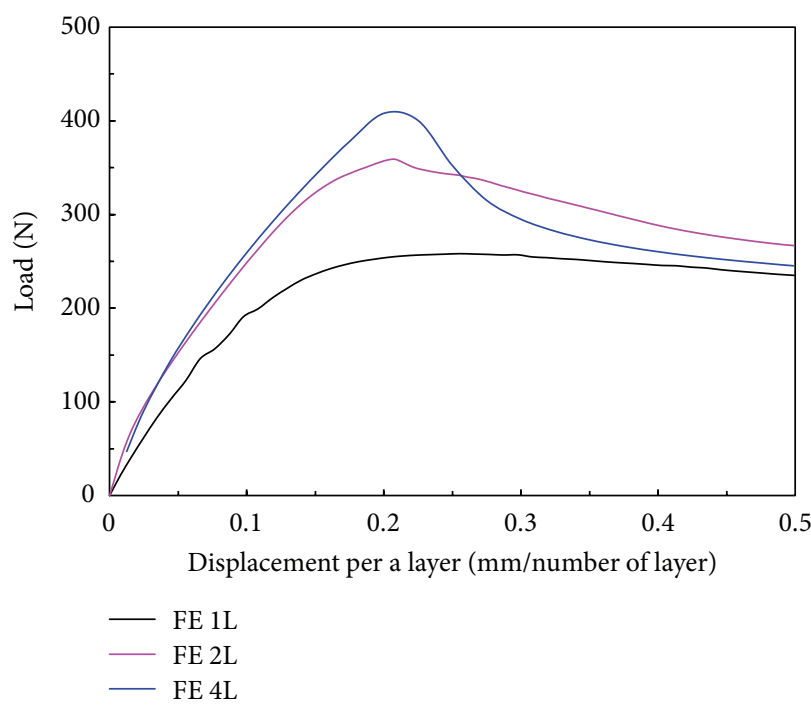

(a) FE models

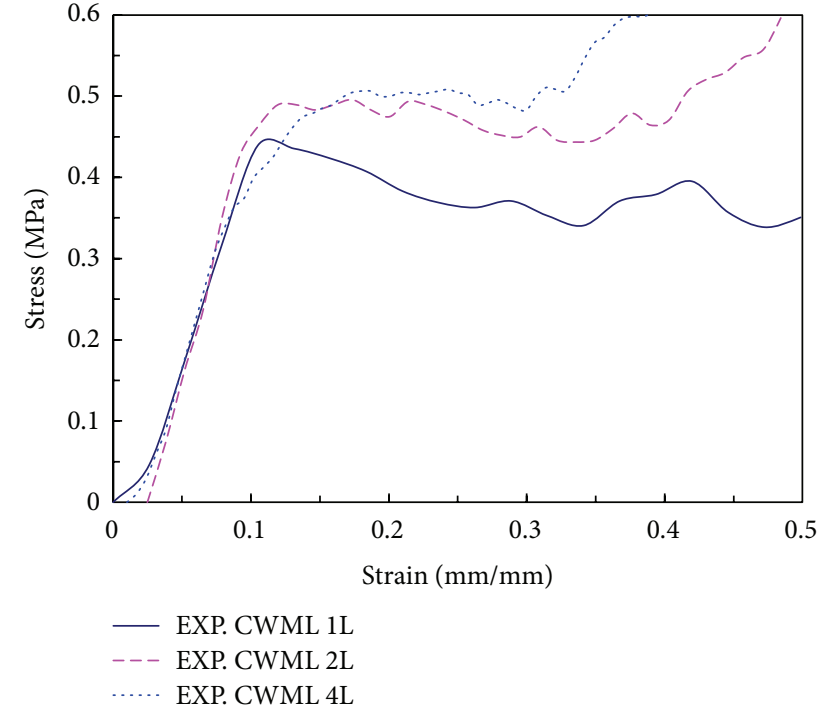

(b) Experiments

FIGURE 15: Load against displacement per a layer total reaction for FE model and experiment [13] and stress-strain plot of CWML experiments.

$(X)$ direction, and (c) hinged with friction, that is, same condition as in (b), but translation in $X$ direction is resisted by friction. Note that in all three cases there is no restraint against rotation. These boundary conditions are only applicable to the end nodes in the case of a strand with multiple corrugation; the intermediate bottom nodes will be free to slide with or without friction. They will also have some constrains against rotation due to the stiffness of the adjoining members. For all the nonlinear studies conducted on the single wave model, the first boundary condition is used; that is, the vertices of a single wave are not allowed any degree of translational freedom. For the analysis conducted to study the effect of friction, the third boundary condition is used. Note that the second boundary condition is the limiting case of the third boundary condition, wherein the value of the friction coefficient is set to zero. Since the truss members can only carry axial forces, it can be shown that the upper limit for friction coefficient is given by

$$
\mu_{\max }=\frac{1}{\tan \varphi}
$$

where $\varphi$ is the base angle of the corrugation wave. The case $\mu=\mu_{\max }$ thus corresponds to the first boundary condition, allowing no translational degree of freedom.

For the investigation of friction, the used contact definition in bottom of CWML model is node-line. The chosen options for the node line contact are 1.0 allowable tensile contact pressure, 0.1 penetration tolerance, Lagrange \& penalty method in contact algorithm, normal to target surface in contact normal, standard behaviour of contact surface, $5 \mathrm{e} 3$ maximum friction stress, and 1.0 static/dynamic ratio. Figure 13 shows node-line contact. Bottom line is rigid. Material properties are bilinear material model as shown in Table 1. Analysis is small deformation as LD OFF and friction coefficient number is increased.

\section{Validation of One-Layer CWML Model}

For validation of a one-layer CWML model which is based on four corrugations with 18 wire strands, it is investigated as changing friction, height, or base length as shown in Figure 14. When curved model as four corrugation is tested, Figure 14(a) shows load against vertical displacement at vertex. It is shown that friction is a reason to increase effective stiffness before yielding and yield load.

Material model in here is bilinear isotropic hardening, and material properties are coming from wire mesh characterisation. Then, as increasing friction with fixed height and base length in Figure 14(a), effective stiffness before yielding and yield load are increased. If the stiffness is reasonably matched with the experiment, yield load will not be matched. If yield load is similar with the experiment, the stiffness will be higher than the experiment. As increasing height with constants of friction coefficient number and base length in Figure 14(b), effective stiffness before yielding and yield load are increased. As based length per unit corrugation with constant of friction coefficient number and height in Figure 14(b) increases, effective stiffness before yielding and yield load are decreased. Thus, the most reasonable effective stiffness before yielding and yield load are based on 0.35 friction coefficient number, $0.35 \mathrm{~mm}$ height, and $5 \mathrm{~mm}$ base length per unit corrugation.

CWML model creates one, two and four layers based on the 0.35 friction coefficient number, $0.35 \mathrm{~mm}$ height, and $5 \mathrm{~mm}$ base length per unit corrugation. As increases number of layer in the CWML model, effective stiffness before yielding and yield load are decreased. When each 
model of the CWML is compared to the experiment, all the CWML models show almost same effective stiffness before yielding. However, yield load is increased as the number of layers increases. Thus, Figure 15(a) shows simulated results of CWML models and Figure 15(b) shows CWML experiments. In Figure 15(a), it shows load against vertical displacement at vertex per a layer. All CWML models have a reasonably matched in the range of effective stiffness before yielding and yield load is increased as that the layers increases number. In Figure 15(b), it shows stress-strain plot for the experiment of CWML, and the effective Young's modulus is almost same. In the experiment, the used cross section area is $20 \mathrm{~cm} \times 20 \mathrm{~cm}$, and it includes space made by corrugation. Thus, FE model may have similar Young's modulus when the model uses the same cross-section area.

\section{Conclusion and Recommendations}

Corrugated wire mesh laminate (CWML) has investigated two parts mainly: (1) development of finite element (FE) model and (2) validation of CWML model.

In the development of FE model, CWML model is based on published material property of stainless steel type 316 , and the published material properties are tested by a solid sample, not a wire mesh. The model is studied about geometry of a single strand, meshing, creation of CWML geometry, boundary condition, structural analysis, linear buckling analysis, and friction. So, the sharp model is of a higher effective stiffness before yielding and a higher yield load than curved the model. As radius in the curved model decreased and friction increases, effective stiffness before yielding and a higher yield load are increased. In addition, as corrugated number is increased, a higher load for the buckling is required.

In the verification of the CWML model, material properties are coming from mechanical tension testing of a plain mesh. The CWML model represents a decreased effective stiffness before yielding and decreased yield load the number of corrugated layers after comparing with experiment increases. However, the CWML model shows a higher effective stiffness because the model is developed with many assumptions like being tightly bonded in all crossed wire, having symmetrical deformation, having around 0.3 friction coefficient, and so on.

Therefore, effective stiffness before yielding and yield load in the CWML model depend on the number of corrugations, the number of corrugated layers, the corrugation angle, opening width, and the wire diameter. For an application of aerospace or biomechanics in the future, the CWML model needs more investigation about friction, boundary condition, and parametric studying.

\section{References}

[1] J. Choi, K. Shankar, A. J. Neely, and A. Fien, "Methods for manufacture of corrugated wire mesh laminates," in Proceedings of the International Conference on Mechanical Engineering, PWASET, Tokyo, Japan, May 2009.
[2] J. Tian, T. J. Lu, H. P. Hodson, D. T. Queheillalt, and H. N. G. Wadley, "Cross flow heat exchange of textile cellular metal core sandwich panels," International Journal of Heat and Mass Transfer, vol. 50, no. 13-14, pp. 2521-2536, 2007.

[3] D. J. Sypeck, "Cellular truss core sandwich structures," Applied Composite Materials, vol. 12, no. 3-4, pp. 229-246, 2005.

[4] J. Caulfield, A. M. Karlsson, and D. J. Sypeck, "Crushing of a textile core sandwich panel," AIAA Journal, vol. 44, no. 6, pp. 1339-1344, 2006.

[5] I. Özbek, B. A. Konduk, C. Bindal, and A. H. Ucisik, "Characterization of borided AISI 316L stainless steel implant," Vacuum, vol. 65, no. 3-4, pp. 521-525, 2002.

[6] D. T. Queheillalt, Y. Katsumura, and H. N. G. Wadley, "Synthesis of stochastic open cell Ni-based foams," Scripta Materialia, vol. 50, no. 3, pp. 313-317, 2004.

[7] E. Smethurst, "A new stainless steel alloy for surgical implants compared to 316 S12," Biomaterials, vol. 2, no. 2, pp.116-119, 1981.

[8] D. G. Poitout, Biomechanics and Biomaterials in Orthopedics, Springer, 1st edition, 2004.

[9] G. He and M. Hagiwara, "Ti-Cu-Ni(Fe,Cr,Co)-Sn-Ta(Nb) alloys with potential for biomedical applications," Materials Transactions, vol. 45, no. 4, pp. 1120-1123, 2004.

[10] M. Zupan, V. S. Deshpande, and N. A. Fleck, "The out-ofplane compressive behaviour of woven-core sandwich plates," European Journal of Mechanics, A/Solids, vol. 23, no. 3, pp. 411421, 2004.

[11] G. W. Kooistra, V. S. Deshpande, and H. N. G. Wadley, "Compressive behavior of age hardenable tetrahedral lattice truss structures made from aluminium," Acta Materialia, vol. 52, no. 14, pp. 4229-4237, 2004.

[12] H. N. G. Wadley, N. A. Fleck, and A. G. Evans, "Fabrication and structural performance of periodic cellular metal sandwich structures," Composites Science and Technology, vol. 63, no. 16, pp. 2331-2343, 2003.

[13] ASTM-D-4255/D-4255M-01, Standard Test Method for in-Plane Shear Properties of Polymer Matrix Composite Materials by the Rail Shear Method, ASTM International, 2007.

[14] LaserExtensometers, EIR, (Electronic Instrument Research), Irwin, Pa, USA, 2007.

[15] "Universityof Alberta. ANSYS Tutorials," 2001, http://www .mece.ualberta.ca/tutorials/ansys/IT/Buckling/Buckling.html. 

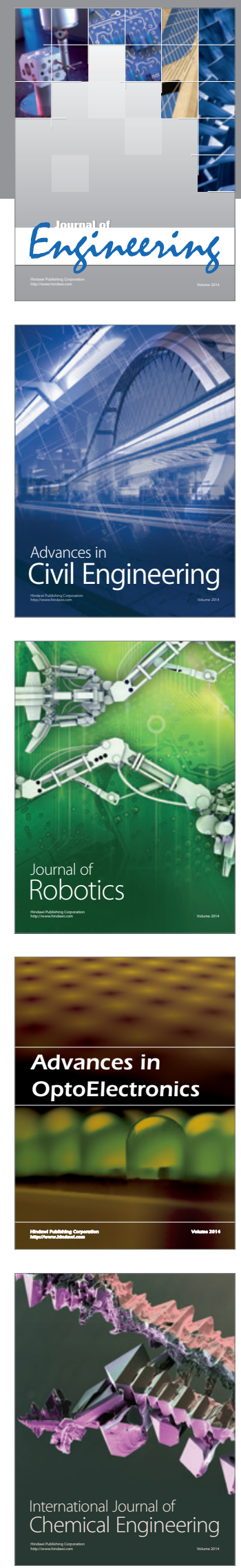

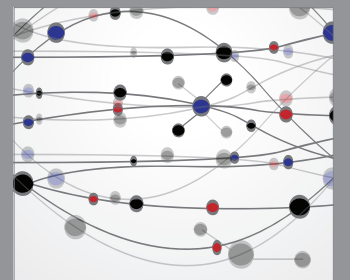

The Scientific World Journal
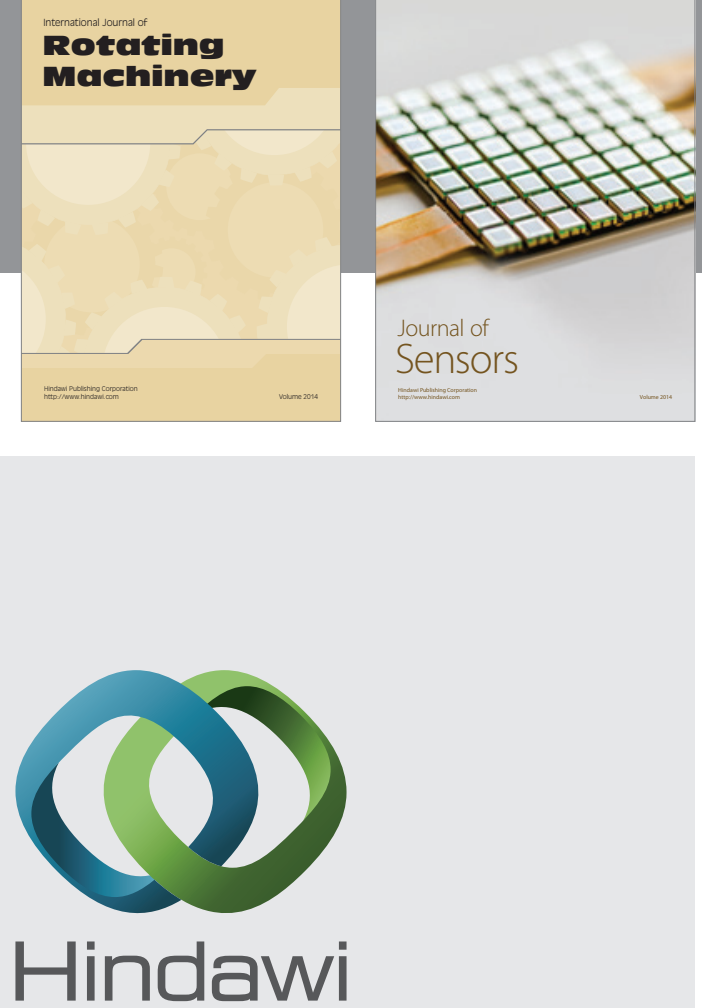

Submit your manuscripts at http://www.hindawi.com
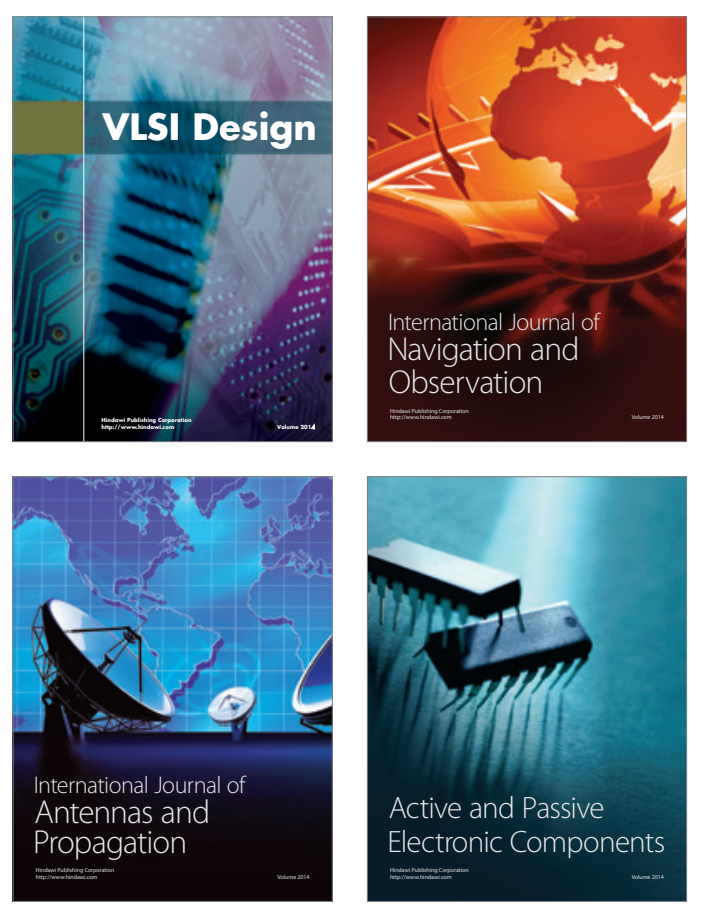
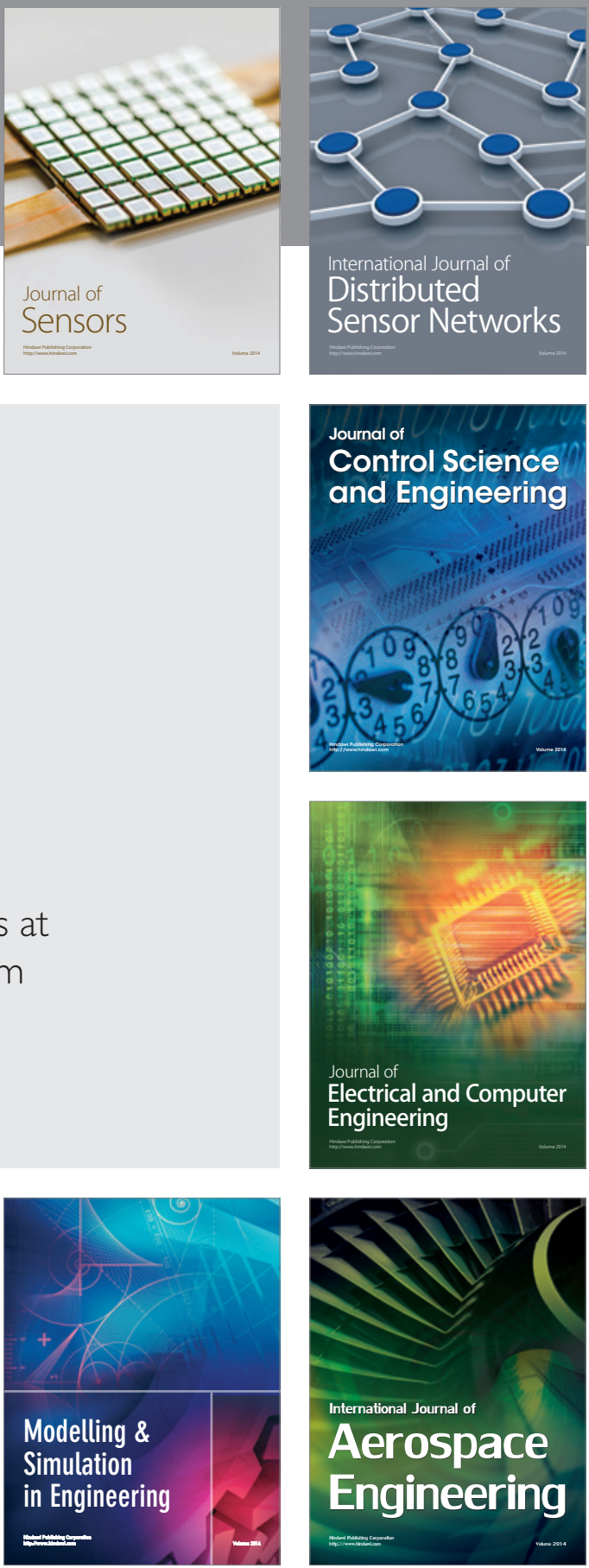

Journal of

Control Science

and Engineering
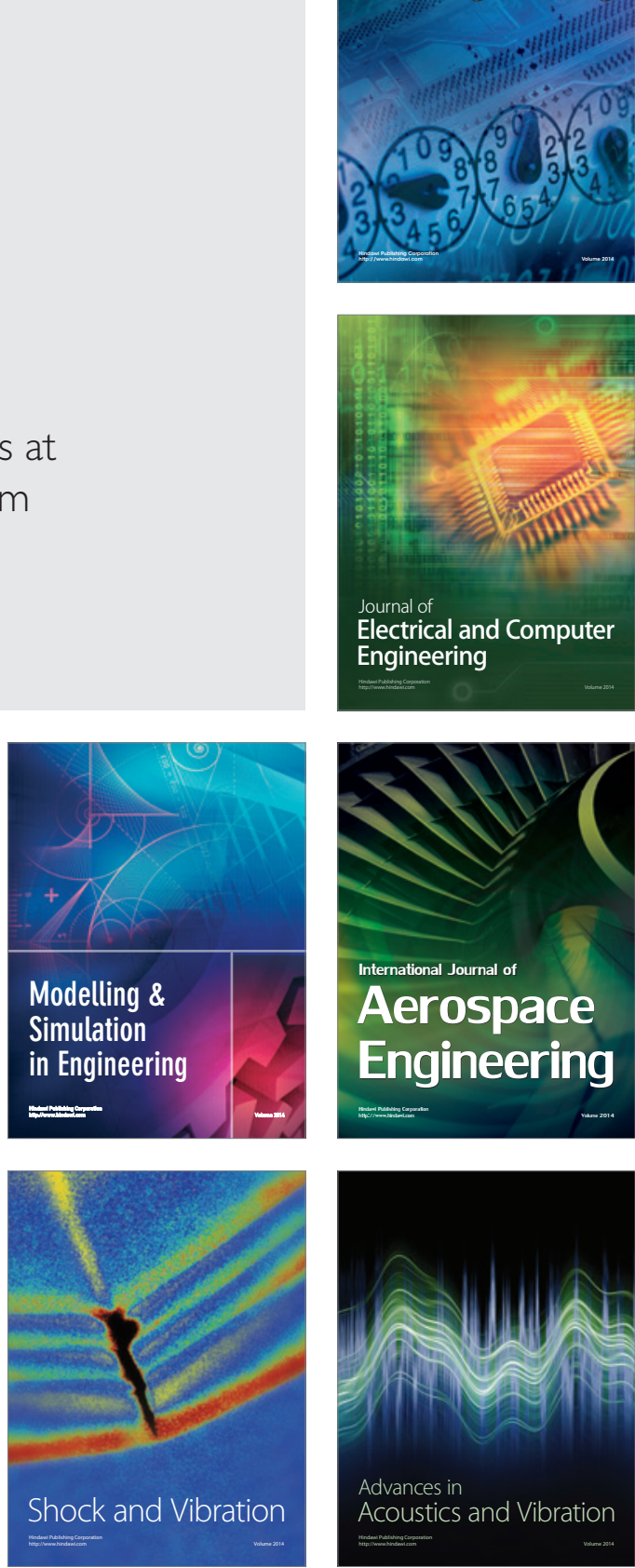